\title{
Design of Brushless DC motor Drive System for Electric Vehicle Applications
}

\author{
Yueying $\mathrm{ZHU}^{1,2, a}$, Xu CAO ${ }^{1, b}$,Shihai $\mathrm{CUI}^{1,2}$ \\ ${ }^{1}$ College of Mechanical Engineering, Tianjin University of Science and Technology, Tianjin, 300222, \\ China \\ ${ }^{2}$ Tianjin Key Laboratory of Integrated Design and On-line Monitoring for Light Industry \& Food \\ Machinery and Equipment, Tianjin, 300222, China \\ aemail: hityueying929@163.com, bemail:haocaoxu666@163.com
}

Keywords: brushless DC motor; control system; mathematical model; simulation

\begin{abstract}
With its advantages of good torque and speed characteristics, high-speed dynamic response, the brushless DC motor is gradually becoming the first choice for electric vehicles. In order to effectively solve the brushless DC motor control problems caused by the non-linear characteristics, so that this type of motor can be preferably applied in electric vehicles. In this study, according to the nonlinear characteristics of brushless DC motor, the mathematical model is established. Rotating speed and current dual-loop control is selected as the control strategy, The control system is analyzed and simulated, the simulation model of the drive motor is established in the MATLAB/Simulink. And dynamic driving characteristics of the motor are analyzed. The simulation results show that mathematical model is accurate. In this design, no static speed difference can be realized and the motor can be quickly started and broke. The study has great significance in improving the electric vehicle dynamic performance and battery efficiency, as well as increasing the driving range.
\end{abstract}

\section{Introduction}

The fundamental characteristic of Brushless DC motor is that it replaces the traditional mechanical commutation with a electronic commutation composed of a logic circuit and a power switch circuit, it transform the DC power into AC power and then sent the AC current to the motor stator windings according to a certain order to produce a stator magnetic field perpendicular to the rotor magnetic field. Brushless DC motor has many outstanding advantages such as it can get better torque speed characteristics, it has a high speed dynamic response, high efficiency, long life, low noise and high speed.

The control system working environment is dynamic, and the other parties of the motor are often unpredictable. This requires the motor can be not only controlled accurately, but also can be actively controlled. Many researchers have been committed to perfect and improve the performance of the motor.

In the simulation design of this paper, a speed and current double closed loop brushless DC motor control system is established using MATLAB/Simulink, the simulation technology oriented electrical schematic diagram. It simulates the control system and analyzes the system performance according to the simulation.

\section{The mathematical model establishment and analysis of the brushless DC motor}

Two-phase conduction star shape with three-phase and six-status is used in the study for its advantages of simple control and excellent performance. Because of the gap magnetic field, counter electromotive force and current are non-sinusoidal, straight and cross axis coordination is not an effective method of analysis. The phase variables of the motor itself are used to establish the mathematical model. For simplicity, the assumptions are as follows:

(1) The magnetic induction of the motor gap is in trapezoidal distribution in space.

(2) The stator slot can be ignored. 
(3) The gap magnetic flux can be ignored in the reaction.

(4) Hysteresis and eddy current losses are ignorable.

(5) The three-phase windings are completely symmetrical.

Since the rotor reluctance does not vary with the rotor position, therefore, self and mutual reluctance of the state windings are constant, and the voltage balance equation of the phase windings can be expressed as:

$\left[\begin{array}{l}u_{a} \\ u_{b} \\ u_{c}\end{array}\right]=\left[\begin{array}{lll}r & 0 & 0 \\ 0 & r & 0 \\ 0 & 0 & r\end{array}\right]\left[\begin{array}{l}i_{a} \\ i_{b} \\ i_{c}\end{array}\right]+\left[\begin{array}{ccc}L & M & M \\ M & L & M \\ M & M & L\end{array}\right] \frac{d}{d t}\left[\begin{array}{l}i_{a} \\ i_{b} \\ i_{c}\end{array}\right]+\left[\begin{array}{c}e_{a} \\ e_{b} \\ e_{c}\end{array}\right]$

Where $u_{\mathrm{a}} 、 u_{\mathrm{b}} 、 u_{\mathrm{c}}$ are the voltage of the stator windings, $i_{\mathrm{a}} 、 i_{\mathrm{b}} 、 i_{\mathrm{c}}$ is the current of the stator windings,$e_{\mathrm{a}} 、 e_{\mathrm{b}} 、 e_{\mathrm{c}}$ are the electromotive force of the stator windings, $\mathrm{r}$ is the resistance of each stator winding, $L$ is the mutual reluctance in each winding, $M$ is the mutual reluctance in each two windings.

Since the three-phase windings are in the star connection, $i_{\mathrm{a}}+i_{\mathrm{b}}+i_{\mathrm{c}}=0$, therefore, $M i_{\mathrm{a}}+M i_{\mathrm{b}}+M i_{\mathrm{c}}=0$, so the formula can be expressed as:

$\left[\begin{array}{l}u_{a} \\ u_{b} \\ u_{c}\end{array}\right]=\left[\begin{array}{lll}r & 0 & 0 \\ 0 & r & 0 \\ 0 & 0 & r\end{array}\right]\left[\begin{array}{l}i_{a} \\ i_{b} \\ i_{c}\end{array}\right]+\left[\begin{array}{ccc}L-M & 0 & 0 \\ 0 & L-M & 0 \\ 0 & 0 & L-M\end{array}\right] \frac{d}{d t}\left[\begin{array}{l}i_{a} \\ i_{b} \\ i_{c}\end{array}\right]+\left[\begin{array}{c}e_{a} \\ e_{b} \\ e_{c}\end{array}\right]$

The equivalent circuit of the Brushless DC motor can be obtained. Where $U_{\mathrm{s}}$ is DC voltage, VT1 - VT6 are power switching devices, VD1-VD6 are freewheeling diodes, and $L M=L-M$, the phase current and electromotive force directions in the figure are the positive direction.

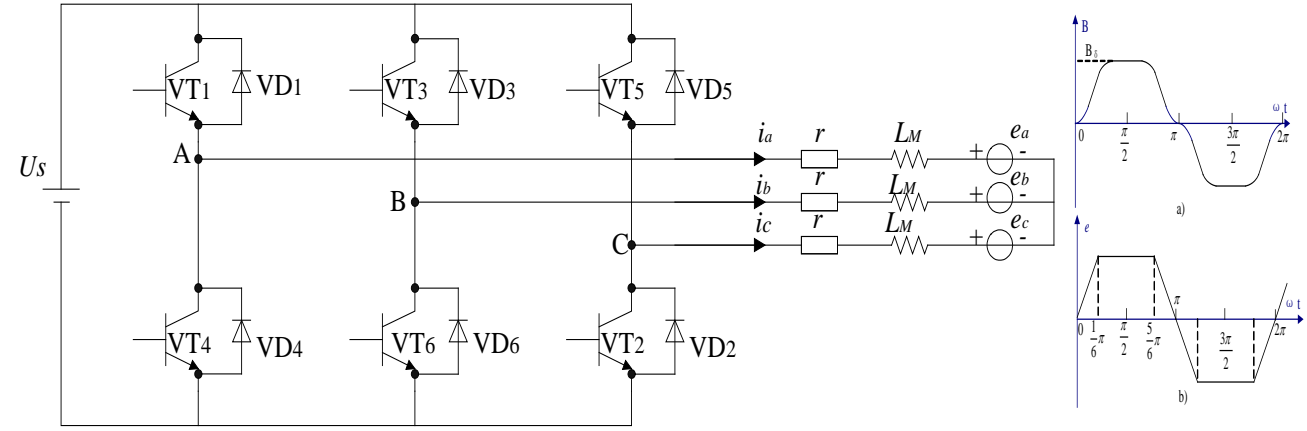

Figure1 The equivalent circuit of the Brushless DC

Figure2 The waveform of flux density and counter electromotive force

The main magnetic flux density of the motor gap distribution waveform $\mathrm{B} \delta$ can be seen in the figure $2 \mathrm{a}$ ) , the counter electromotive force waveform with $120^{\circ}$ flat top width can be seen in the figure $2 \mathrm{~b}$ ). Furthermore, the line voltage model of the brushless DC motor can be described in(3) and (4).

$$
\begin{aligned}
& \left\{\begin{array}{l}
L_{M} \frac{d i_{a}}{d t}+r i_{a}+e_{a}-\left(L_{M} \frac{d i_{c}}{d t}+r i_{c}+e_{c}\right)=0 \\
L_{M} \frac{d i_{b}}{d t}+r i_{b}+e_{b}-\left(L_{M} \frac{d i_{c}}{d t}+r i_{c}+e_{c}\right)=U_{s} \\
i_{a}+i_{b}+i_{c}=0
\end{array}\right. \\
& \left\{\begin{array}{l}
L_{M} \frac{d i_{b}}{d t}+r i_{b}+e_{b}-\left(L_{M} \frac{d i_{c}}{d t}+r i_{c}+e_{c}\right)=U_{s} \\
i_{b}+i_{c}=0
\end{array}\right.
\end{aligned}
$$

\section{The simulation of the brushless DC motor control system in the MATLAB/Simulink}

In the figure 3, the DC power module in Simulink/SimPower System is directly used, and the voltage is $450 \mathrm{~V}$. 


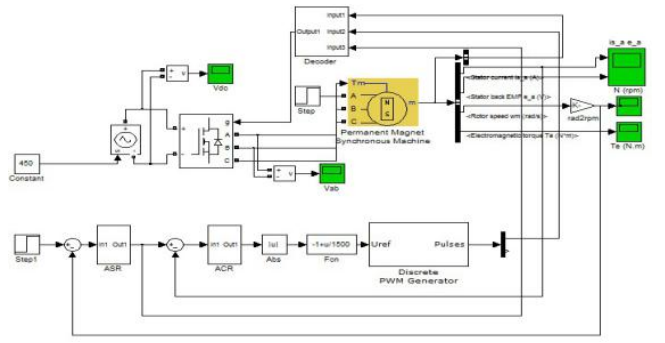

Figure 3 The DC power module

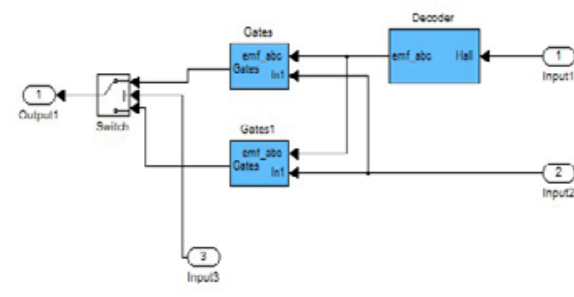

Figure 4 The change phase logic control module

The control signal of inverter bridge switching device can be obtained by the combination of Hall sensor signal, PMW signal and speed deviation signal decode. The function can be realized by the change phase logic control module. So that the inverse change bridge control and the reversible speed regulation can be realized. The module can be seen as the figure 4 .

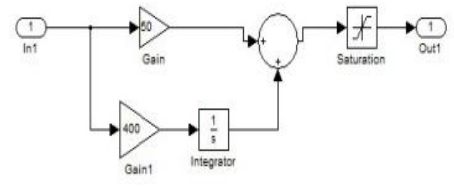

Figure5 The ASR module

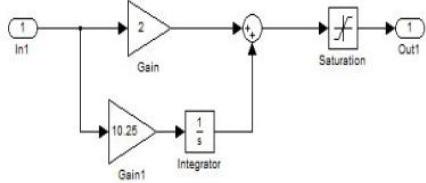

Figure6 The ACR module

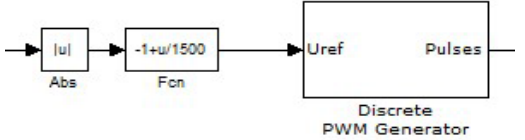

Figure7 The level converter and generating link

The speed and current double-loop control is used in the study, for the inner is speed loop, and the current is the outer loop. The ASR and the ACR can be seen in the figure5 and 6. PI controller is used in the module.

The control of level conversion and the PMW structure are shown in the figure7.Abs is the absolute value function in MATLAB, the current regulation signals can be converted to positive value and passed to the generator by it. Fcn is S-Function, a kind of system function. The current signal can be transferred into the PMW duty ratio by Fcn. The PMW generator is Discrete PWM Generator module in Simulink.

\section{The system simulation and result analysis}

(1) Start and step load simulation

Respectively, at the time of $0.1 \mathrm{~s}$, the speed of $2000 \mathrm{r} / \mathrm{s}$ and the load of $3 \mathrm{~N} \cdot \mathrm{m}$ is given to the motor. The results can be obtained after the simulation in the Simulink, they can be seen at the following figures.

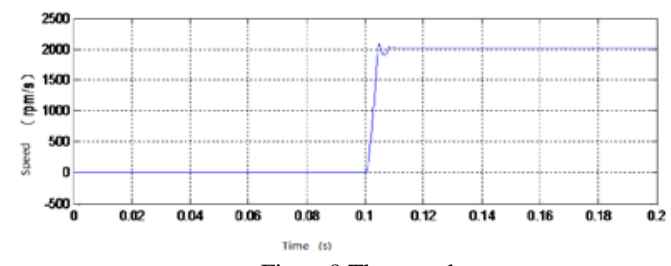

Figure8 The speed response

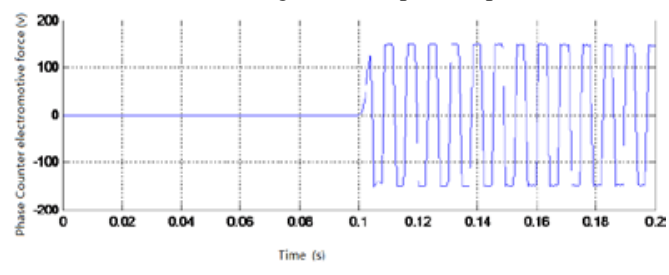

Figure10 The stator phase counter electromotive force

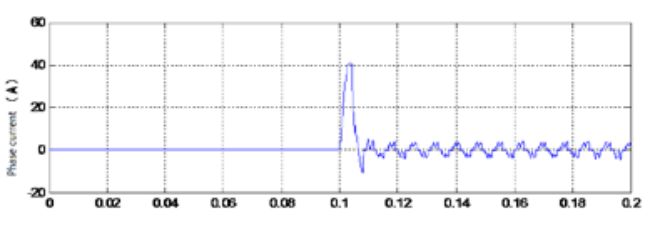

Figure9 The stator phase current

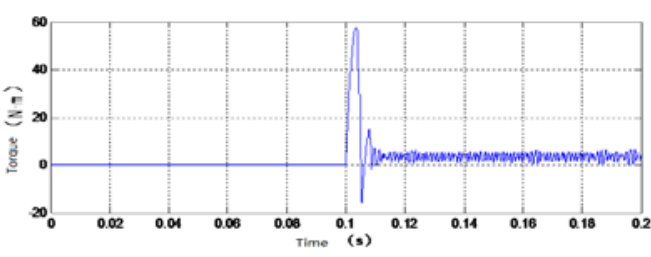

Figure11 The torque response

Simulation results analysis: according to the waveform, the maximum ultra conditioning $M_{P}=\frac{80}{2000} \times 100 \%=4 \%$; the rise time $t_{r}=4 \times 10^{-3} \mathrm{~s}$; the time adjustment $t_{s}=7 \times 10^{-3} \mathrm{~s}$.

(2) The simulation under given speed

The given speed waveform is shown in the following figure12, after the simulation in the Simulink, the results are shown in the following figures. 


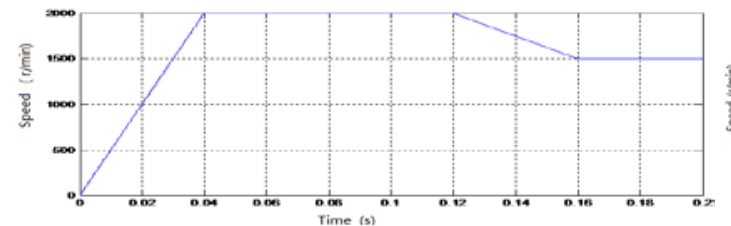

Figure12 The speed of the motor
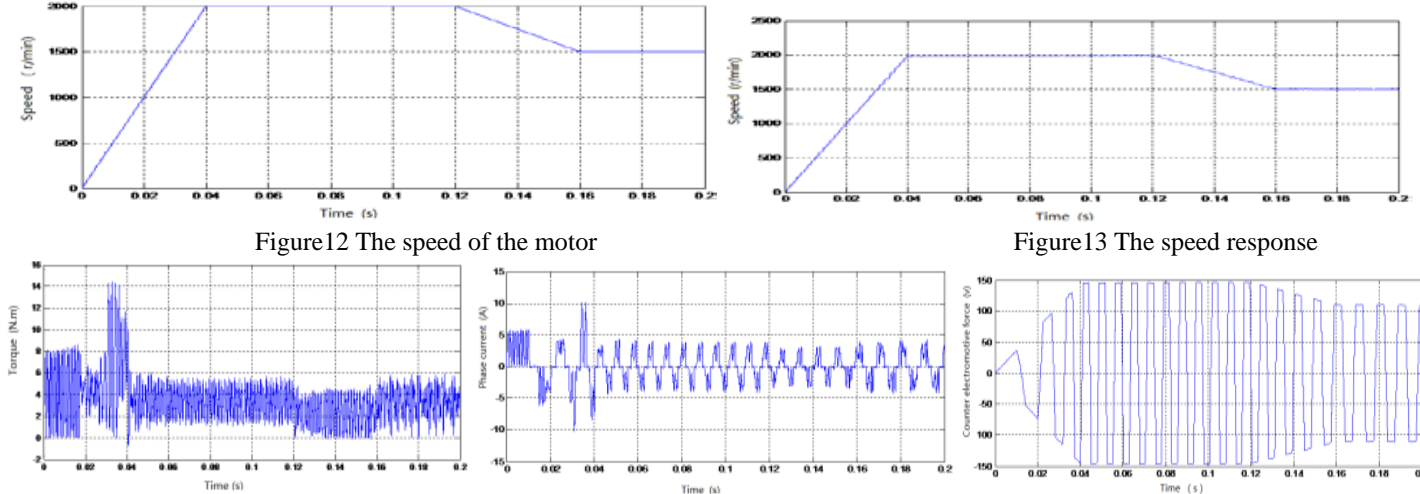

Figure13 The speed response

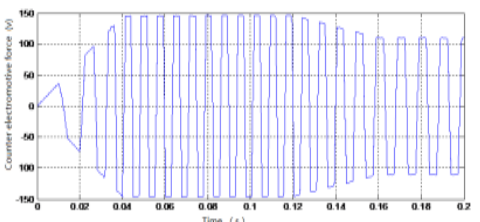

Figure14 The torque response

Figure15 The stator phase current response Figure16 The stator phase counter electromotive force response

The simulation results can be seen, the control system has good speed response.

(3) The simulation under given load torque.

The given load torque waveform is shown in the figure17, after the simulation in the Simulink, the results are shown in the following figures.

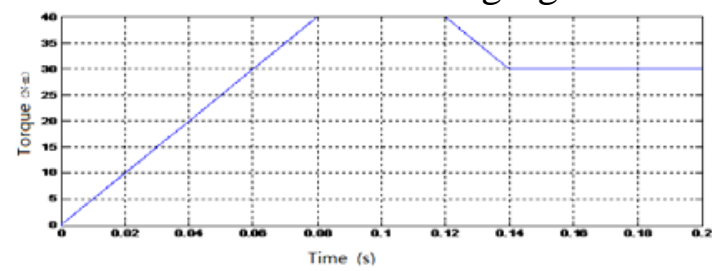

Figure17 The torque of the motor

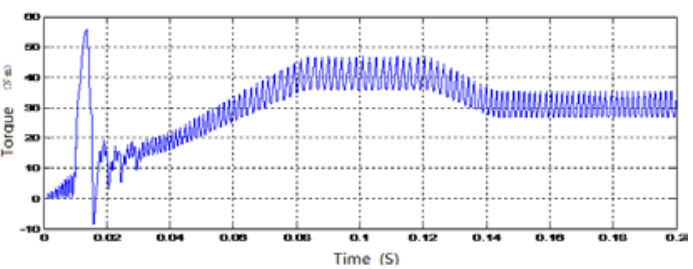

Figure18 The torque response
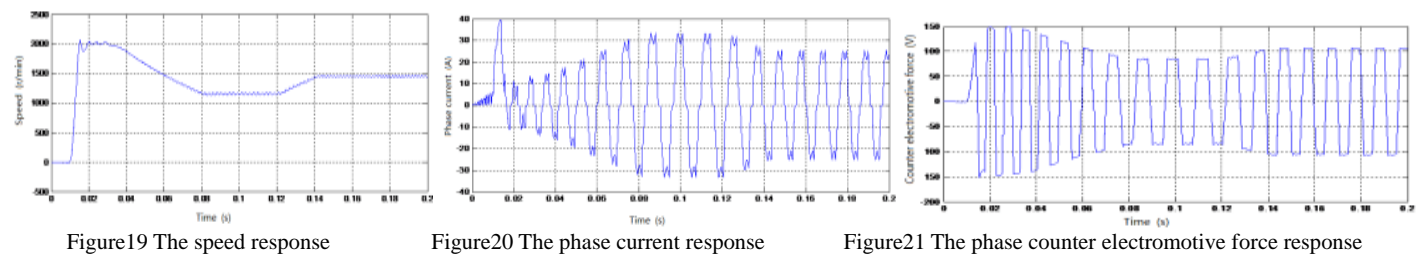

Figure19 The speed response Figure20 The phase current response Figure21 The phase counter electromotive force response

The simulation results can be seen, the control system has good torque response.

(4)The simulation under given speed and load torque respectively.

The given speed and load torque waveform are respectively shown in the following figures.

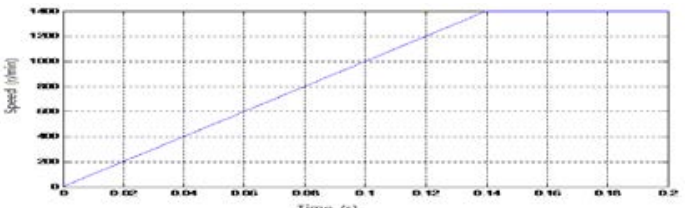

Figure22 The speed of the motor

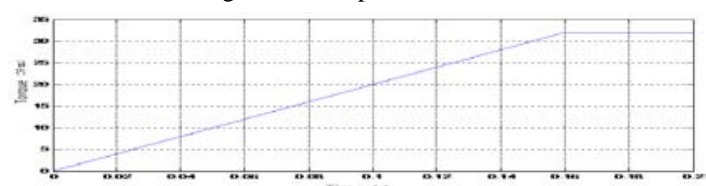

Figure24 The torque response

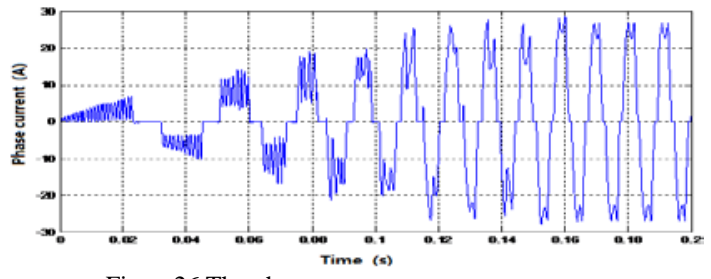

Figure26 The phase current response

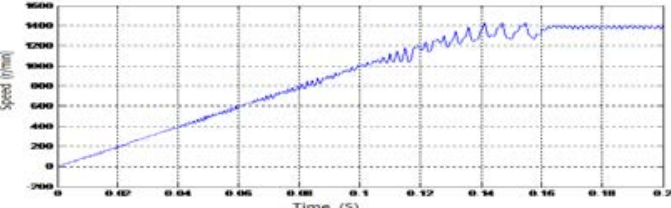

Figure23 The speed response

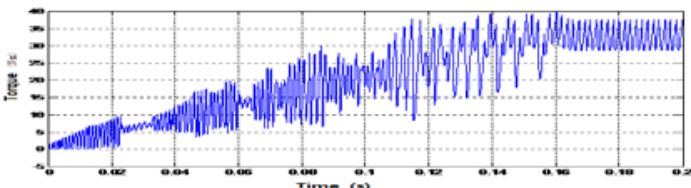

Figure25 The torque response

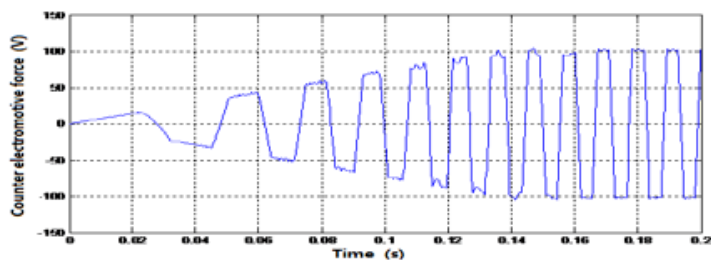

Figure27 The phase counter electromotive force response

The simulation results can be seen, the control system has good speed and torque response.

\section{Conclusions}

In this study, a mathematical model of brushless DC motor control system, and the equivalent circuit diagram are established. A calculation method of motor counter electromotive force is 
proposed in the study, so that, it laid the foundation of the control system simulation. The steady-state performance of the motor is dynamically simulated, further more, the line voltage model of the brushless DC motor is established.

In the simulation design, the speed control of motor is the main function of the system. Based on the Hall position sensor, commutation logic circuit is designed. No static speed difference can be realized and the motor can be quickly started and broke. Speed and current double-loop control is used in the study. Voltage can be obtained through the speed feedback, after comparing with the given value, the pulse width sequence is obtained which is in certain frequency and adjustable duty ratio. After the power amplifier, the turn-on and turn-off time of power electronic components in the main circuit are controlled by the system, and then the speed of the motor is preferably changed.

The correctness of the model is verified by the system simulation in the MATLAB, in addition, the feasibility of the design scheme is verified by the waveform analysis. The study has great significance in improving the electric vehicle dynamic performance and battery efficiency, as well as increasing the driving range.

\section{References}

[1] Yueying Zhu, Dafang Wang, Guifan Zhao, etal. Research Progress of Switched Reluctance Motor Drive System. IEEE International Conference on Mechatronics and Automation, Changchun, China, 2009: 784-789.

[2] Kazuak S. Kaoru K., Toshiaki K.. Development of electric motors for the TOYTA hybtid vehicle prius[J]. IEEE Transaction on Industry Applications, 2000, 8(4): 3-44

[3] Pillay P, Krishnan R. Modeling, simulation, and analysis of permanent-magnet motor drives (1): The permanent-magnet synchronous motor drives [J]. IEEE Industry Applications, 1989, 25(2): 265-273

[4] Natarajan R., Imece A.. Development of Generation Traction Motor for FCV[J]. 2000, 17(7): 12-13

[5] Xiao Fang, Zhang Jiqiang, Tu Hailing. Electrie Vehicles-Clean driving that presages the $21^{\text {st }}$ century[M]. Beijing: Metallurgical Industry Press, 2002: 11-22 